\title{
Constitutive Expression of the Granulocyte-Macrophage Colony-stimulating Factor Gene in Acute Myeloblastic Leukemia
}

\author{
Diane C. Young, Katherine Wagner, and James D. Griffin \\ Division of Tumor Immunology, Dana-Farber Cancer Institute, Boston, Massachusetts 02115
}

\begin{abstract}
Expression of the granulocyte-macrophage colony-stimulating factor (GM-CSF) gene was studied by Northern blot analysis in normal human hematopoietic cells and a series of leukemias. GM-CSF messenger ( $m$ )RNA was detected in activated $T$ cells, but not in normal bone marrow cells, monocytes, or nonactivated $T$ cells. In contrast, leukemic cells from 11 of 22 cases of acute myeloblastic leukemia expressed GM-CSF transcripts. Biologically active CSF was detected in supernatant conditioned by 6 of these 11 leukemias. Expression of the GM-CSF gene was not detected in "common" (pre-B cell) acute lymphoblastic leukemia (11 cases tested) or chronic myeloid leukemia (4 cases tested). These results show that the GM-CSF gene is constitutively expressed in a subset of patients with AML, and further suggest that expression of this gene could contribute to the abnormal growth properties characteristic of AML.
\end{abstract}

\section{Introduction}

Acute myeloblastic leukemia (AML) ${ }^{1}$ is a highly lethal neoplasm characterized by excessive proliferation and aberrent differentiation of immature myeloid cells. The cause(s) of AML, and the mechanisms whereby leukemic cells have escaped from normal regulatory events, are unknown. In vitro, only a small subset of leukemic cells from most patients with AML can be induced to proliferate in semisolid media (1). These clonogenic leukemic cells are capable of self-renewal in vitro $(2,3)$, are less "differentiated" than their progeny (4), and have been shown to be actively proliferating in vivo (5). For these reasons, it is likely that these cells, or closely related cells, function as leukemic stem cells in vivo and serve to maintain and expand the leukemic cell population (6). Maximum proliferation of these clonogenic cells in vitro usually requires the addition of glycoprotein growth factors termed colony-stimulating factors (CSFs), although we and others have shown that autonomous proliferation can also be observed $(7,8)$. The recent cloning of the genes for the known

Address reprint requests to Dr. Griffin. Dr. Griffin is a Scholar of the Leukemia Society of America.

Received for publication 20 June 1986 and in revised form 18 August 1986.

1. Abbreviations used in this paper: ALL, acute lymphoblastic leukemia; AML, acute myeloblastic leukemia; CFU-GM, granulocyte/monocyte progenitor cells; CML, chronic myeloid leukemia; CSF, colony-stimulating factor; GM, granulocyte macrophage; PMA, phorbol myristate acetate; L-CFC, leukemic colony-forming cells; SSC, standard saline citrate.

J. Clin. Invest.

(c) The American Society for Clinical Investigation, Inc.

0021-9738/87/01/0100/07 \$1.00

Volume 79, January 1987, 100-106 human CSFs (9-12) and the subsequent production of recombinant proteins has made it possible to investigate the individual effects of the CSFs on in vitro AML cell proliferation. Granulocyte-macrophage (GM)-CSF is the most active of the human CSFs, although G-CSF appears to be active independently and is synergistic with GM-CSF in many cases, particularly in determining maximum colony size $(13,14)$. GM-CSF is produced by $T$ lymphocytes activated by mitogen, antigen, or phorbol ester, but not by resting $T$ cells $(9,15)$. Hematopoietic cells other than $\mathrm{T}$ cells, including granulocytes and monocytes, are not known to produce GM-CSF in a resting or activated state. In particular, there is no evidence that normal hematopoietic progenitor cells can produce GM-CSF and thus stimulate their own proliferation in an "autocrine" manner.

The finding that GM-CSF is an effective growth factor for AML cells $(13,14)$ and our observation of limited autonomous proliferation of AML cells in vitro (16) prompted us to investigate the expression of the GM-CSF gene in leukemic cells and their normal counterparts. Using Northern blot analysis, expression of the GM-CSF gene was detected in the leukemic cells of 11 of 22 cases of AML, 0 of 11 cases of common ALL, and 0 of 4 cases of CML. Expression of the GM-CSF gene in normal hematopoietic cells was limited to activated $T$ lymphocytes. Monocytes, granulocytes, and bone marrow cells did not express the GM-CSF gene even when stimulated with chemical agents known to cause "activation" of such cells. These results suggest that constitutive expression of the GM-CSF gene occurs frequently and specifically in $\mathrm{AML}$, and further suggests that expression of this gene may contribute to the abnormal growth properties of AML.

\section{Methods}

Leukemic cells. Bone marrow aspirate samples were obtained at diagnosis and the mononuclear fraction isolated by sedimentation on Ficoll-Hypaque density gradients. Samples were cryopreserved in $10 \%$ dimethyl sulfoxide (DMSO) in the vapor phase of liquid nitrogen until use. The diagnosis of AML was established by morphology, cytochemical staining, and surface marker analysis using a panel of antimyeloid monoclonal antibodies (17). In all experiments, leukemic cells were depleted of T cells by rosetting with sheep erythrocytes, and depleted of monocytes by plastic adherence at $37^{\circ} \mathrm{C}$. Bone marrow and peripheral blood specimens were selected for study only where they were shown to contain $>95 \%$ blasts.

Normal cells. Marrow cells were aspirated from normal volunteers and E-rosetted as above. Monocytes were prepared from blood mononuclear cells by removing E-rosetting cells and then collecting plastic adherent cells. $T$ cells were prepared by E-rosetting and further depleted of monocytes by removing adherent cells. In some experiments, marrow cells, monocytes, or T cells were cultured for $24 \mathrm{~h}$ at $37^{\circ} \mathrm{C}$ in RPMI $1640,10 \%$ fetal bovine serum, with either $10^{-10} \mathrm{M}$ phorbol myristate acetate (PMA, Sigma Chemical Co., St. Louis, MO) or $500 \mathrm{U} / \mathrm{ml}$ recombinant gamma-interferon (Biogen, Cambridge, MA).

Leukemic colony-forming cell assay. All samples were assayed for the formation of leukemic colonies in the presence and absence of ex- 
ogenous GM-CSF. Leukemic colony forming cells (L-CFC) were measured in a double layer agar assay modified as previously described (13). Leukemic cells $\left(5 \times 10^{4} / 0.5 \mathrm{ml}\right)$ were cultured in $0.3 \%$ agar $(0.5 \mathrm{ml})$ over a $0.5 \%$ agar underlayer $(0.5 \mathrm{ml})$. Growth factors were added to the underlayer in some experiments. The medium was Iscove's modified Dulbecco's minimal essential medium (IMDM, Gibco, Grand Island, NY) containing $20 \%$ fetal bovine serum (FBS) supplemented with glutamine and penicillin-streptomycin. At 7-10 d, the agar overlayers were removed and dried onto glass slides under filter paper. The dried agar overlayers were fixed in acetone-citrate-methanol and colonies stained in situ for chloroacetate esterase and alpha-naphthyl acetate esterase activities to identify cells of myeloid lineage. L-CFC included both colonies (defined as aggregates of 20 or more cells) and clusters (8-19 cells). In studies where GM-CSF was added to leukemic cells, recombinant human GMCSF (9) was obtained from Dr. Steven Clark and Dr. Gordon Wong, Genetics Institute, Cambridge, MA. The GM-CSF was in medium conditioned by $\mathrm{CHO}$ cells transfected with the $\mathrm{P} 91023$ (B) expression vector containing the human GM-CSF cDNA, used at a final dilution of 1:1000. Mock (vector-only) transfected CHO cell medium was used as a control. Pilot experiments showed mock medium contained neither stimulatory nor inhibitory activities for normal or L-CFC.

CSF assays. The amount of CSF activity secreted by normal cell populations or leukemic cells was assayed by culturing cells at $1 \times 10^{6}$ cells $/ \mathrm{ml}$ in RPMI 1640 with $10 \%$ fetal bovine serum for $48 \mathrm{~h}$. The cells were then removed by centrifugation and the media screened for CSF using a rapid, quantitative $\left[{ }^{3} \mathrm{H}\right]$ thymidine incorporation assay described previously (18). Briefly, myeloblasts were purified $\sim 100$-fold from the peripheral blood of patients with chronic myeloid leukemia (CML) using specific monoclonal antibodies and an immune rosetting technique. 1 $\times 10^{4}$ progenitor cells were cultured in $150 \mu \mathrm{l}$ RPMI 1640 with $10 \%$ FBS and varying concentrations of test supernatants for $48 \mathrm{~h}$ in 96-well microtiter plates. Controls included medium only or $10 \%$ GCT medium (giant cell tumor-conditioned medium, Gibco) as a standard CSF source (19). $4 \mathrm{~h}$ prior to cell harvest, $1 \mu \mathrm{Ci}$ of $\left[{ }^{3} \mathrm{H}\right]$ thymidine was added in 20 $\mu \mathrm{l}$ of RPMI 1640. Cells were harvested on an automatic cell harvester and $\left[{ }^{3} \mathrm{H}\right]$ thymidine incorporation measured. Each assay was performed in triplicate. For comparative purposes, a stimulation index (SI) was calculated from the formula: $\mathrm{SI}=\mathrm{cpm}$ test sample/cpm medium control.

Normal marrow granulocyte/monocyte progenitor cells (CFU-GM) were assayed in a double layer agar system as described above for L-CFC. Marrow was obtained by aspiration from normal volunteers, and light-density mononuclear cells were depleted of adherent cells by plastic adherence. CFU-GM were enumerated on day 7, and cluster/ colony composition determined by in situ staining for alpha naphthyl acetate esterase (monocytes) and chloroacetate esterase (granulocytes) (reagents from Sigma Chemical Co.). In some experiments, a rabbit antiGM-CSF serum was included in these cultures. This antiserum was raised against purified recombinant GM-CSF and kindly supplied by Dr. Steven Clark, Genetics Institute. This antiserum was shown in pilot experiments to neutralize the CFU-GM growth promoting effects of GM-CSF, but not G-CSF or M-CSF (data not shown).

Northern blots. $100-200 \times 10^{6}$ cells were lysed in $4 \mathrm{M}$ guanidium isothiocyanate and layered over $5.7 \mathrm{M}$ cesium chloride. The RNA pellets were recovered following centrifugation at $100,000 \mathrm{~g}$ at $20^{\circ} \mathrm{C}$ for $18 \mathrm{~h}$, resuspended in water and precipitated with ethanol. $10 \mu \mathrm{g}$ samples were run on $1.2 \%$ agarose gels containing $6 \%$ formaldehyde. All gels were stained with ethidium bromide to visualize $28 \mathrm{~S}$ and $18 \mathrm{~S}$ ribosomal RNA bands. These bands were used to confirm that $(a)$ approximately equivalent amounts of RNA were loaded in each gel lane, and $(b)$ there was no obvious degradation of RNA. RNA was transferred to a synthetic nylon transfer membrane (Gene Screen Plus, E. I. Dupont de Nemours $\&$ Co., Wilmington, DE) using $10 \times$ standard saline citrate (SSC) $(1$ $\times \mathrm{SSC}=150 \mathrm{mM} \mathrm{NaCl}, 15 \mathrm{mM}$ citrate, $\mathrm{pH} \mathrm{7.0)}$.

Membranes were prehybridized at $60^{\circ} \mathrm{C}$ in $1 \%$ sodium dodecyl sulfate (SDS), $1 \mathrm{M} \mathrm{NaCl}, 10 \%$ dextran sulfate, then hybridized in the same solution to which $100 \mu \mathrm{g} / \mathrm{ml}$ salmon sperm DNA and $2.5 \times 10^{5} \mathrm{cpm} /$ $\mathrm{ml}{ }^{32} \mathrm{P}$-labeled probe were added. Membranes were washed in $2 \times \mathrm{SSC}$ for $10 \mathrm{~min}, 2 \times \mathrm{SSC} / 1 \% \mathrm{SDS}$ for $1 \mathrm{~h}$ at $60^{\circ} \mathrm{C}$, and $0.1 \times \mathrm{SSC}$ for $1 \mathrm{~h}$ at room temperature. After drying, membranes were exposed to $\mathrm{x}$-ray film with intensifying screens.

DNA probes were labeled to a specific activity of $\sim 10^{9} \mathrm{cpm} / \mu \mathrm{g}$ using hexanucleotide primers and $\left.{ }^{32} \mathrm{P}\right] \mathrm{dCTP}$ by the method of Feinberg and Vogelstein (20). The GM-CSF probe was the Eco RI-Aha III fragment of cloned human GM-CSF cDNA. This fragment was cut out of the SP64 plasmid vector and separated from plasmid DNA by gel electrophoresis prior to labeling. The plasmid was generously provided by Dr. Gordon Wong and Dr. Steven Clark, Genetics Institute, Cambridge. In some experiments, transfer membranes were washed free of GM-CSF probe and rehybridized with a cDNA probe for a $T$ cell-specific marker, the constant region of $\mathrm{T}$ cell antigen receptor alpha chain (21), provided by Dr. Ellis Reinherz, DFCI.

\section{Results}

The FAB classification (22) and colony forming ability of the leukemic cells from 22 adult cases of AML are shown in Table I. In 9 of 22 cases there was autonomous growth of $>50$ colonies or clusters per $5 \times 10^{4}$ cells plated. In 15 of 22 cases, the addition of exogenous GM-CSF to the cultures resulted in increased colony number (by twofold) or larger colony size (increase in colony diameter by twofold) as previously reported (7). In five cases, there was no colony or cluster formation spontaneously or in response to GM-CSF. In all cases, the leukemic nature of the colonies was established by morphologically demonstrating blasts in fixed, stained sections of the agar cultures.

\section{Table I. Leukemic Colony Growth With and Without GM-CSF}

\begin{tabular}{llrrl}
\hline & & \multicolumn{2}{c}{ L-CFC $/ 5 \times 10^{4}$ cells } & \\
\cline { 3 - 4 } Case no. & FAB* & Control & GM-CSF & $\begin{array}{l}>\text { 2-fold increased L-CFC } \\
\text { size with GM-CSF }\end{array}$ \\
\hline 1 & M2 & 10 & 31 & + \\
2 & M1 & 82 & 321 & + \\
3 & M4 & 109 & 550 & + \\
4 & M2 & 0 & 465 & + \\
5 & M5B & 4 & 677 & + \\
6 & M1 & 325 & 380 & + \\
7 & M4 & 0 & 1 & - \\
8 & M1 & 55 & 83 & - \\
9 & M0 & 0 & 19 & + \\
10 & ND & 0 & 423 & + \\
11 & M4 & 12 & 12 & + \\
12 & M4 & 0 & 0 & - \\
13 & M4 & 0 & 45 & + \\
14 & M4 & 0 & 87 & + \\
15 & M5 & 176 & 192 & - \\
16 & M5 & 0 & 2 & - \\
17 & M5 & 708 & 652 & - \\
18 & ND & 219 & 500 & + \\
19 & ND & 65 & 207 & + \\
20 & M4 & 0 & 8 & + \\
21 & M1 & 0 & 1 & - \\
22 & M2 & 705 & 821 & + \\
& & & & + \\
\hline & & & & +
\end{tabular}

* French-American-British classification system (22); ND, not determined.

${ }^{\ddagger}$ L-CFC, clonogenic leukemia cells, includes clusters (8-19 cells) plus colonies ( 20 or more cells).

"Cases in which there was "spontaneous" L-CFC growth were scored for increased size (colony diameter $>2$-fold increase) in response to added GM-CSF. 
The expression of the GM-CSF gene was assayed by Northern blot analysis in normal blood and marrow cells and in a series of leukemic marrow samples (Fig. 1). The normal cell populations were purified to $>95 \%$ homogeneity ( $\mathrm{T}$ cells and monocytes) and the degree of purity established by surface antigen analysis. Monocyte preparations contained $<1 \% \mathrm{~T} 11$ and $\mathrm{T}$ cell preparations < 1\% Mo2-positive cells (23). Marrow mononuclear cells were also depleted of E-rosetting and adhering cells and contained less than $1 \%$ of either T11+ or Mo2+ cells. All leukemic samples were similarly treated and contained $<1 \% \mathrm{~T} 11+$ cells. Normal marrow mononuclear cells, normal monocytes, and resting $\mathrm{T}$ cells did not express detectable GM-CSF message (Fig. $1 E$ ). Activation of T cells with PMA $\left(10^{-10} \mathrm{M}, 18 \mathrm{~h}\right)$ induced expression of the GM-CSF gene as previously described (9). In contrast, treatment of normal monocytes with PMA or gamma-interferon $(\gamma$-IFN, $500 \mathrm{U} / \mathrm{ml}, 18 \mathrm{~h})$ did not induce the GM-CSF gene (Fig. 1, E). Similarly, culture of T-depleted normal marrow cells with PMA or $\gamma$-IFN did not result in detectable expression of the GM-CSF gene.

In contrast to normal marrow cells, in 11 of 22 cases of AML (Fig. 1, $A-D$ ), mRNA for GM-CSF was present. The amount of GM-CSF mRNA varied from case to case, but the size of GM-CSF message was approximately the same $(1.0 \mathrm{~kb})$ as that found in activated T cells (Fig. $1 A$ and $E$ ).

Because of our observation that activated $T$ cells were capable of expressing the GM-CSF gene, additional measures were taken to exclude the possibility that detection of GM-CSF transcripts in AML cells was due to occult contamination of leukemic samples by endogenously activated normal T cells. All AML blots were washed and rehybridized with a probe to the alpha chain of the $T$ cell receptor (21). No case contained detectable $T$ cell mRNA (data not shown). These results suggest that expression of the GM-CSF gene occurs constitutively in a substantial pro-

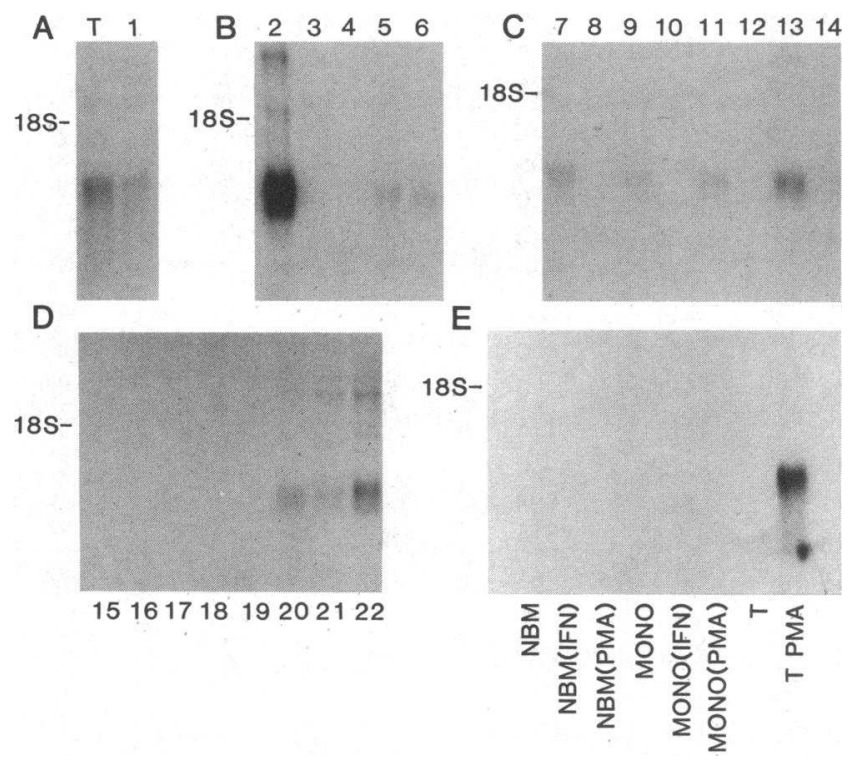

Figure 1. Northern blot analysis of GM-CSF RNA in normal and leukemic cells. Total cellular RNA was fractionated on agarose gels, transferred to nylon membranes, and hybridized with a ${ }^{32} \mathrm{P}$-labeled GM-CSF cDNA probe. Panels $A-D$ show AML cases 1-22 ("T" in panel $A$ indicates PMA-stimulated T cells). Panel $E$; NBM, normal bone marrow mononuclear cells; IFN, gamma-interferon $(500 \mathrm{U} / \mathrm{ml}$ $\times 24 \mathrm{~h}$ ), PMA $\left(10^{-10} \mathrm{M} \times 24 \mathrm{~h}\right)$; Mono, monocytes.

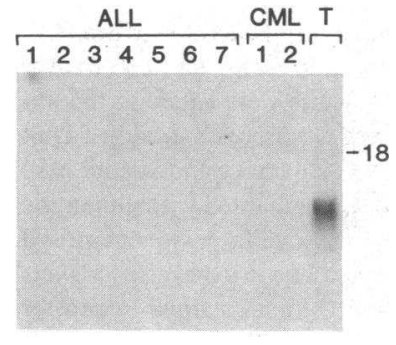

Figure 2. Northern blot analysis of GM-CSF RNA in ALL and CML. See legend to Fig. 1. Total cellular RNA from seven cases of ALL and two cases of CML are shown. T, PMA-stimulated T cells.

portion of cases of AML, but not in normal marrow or blood myeloid cells.

In an effort to understand the significance of the apparent expression of the GM-CSF gene in AML, other acute and chronic leukemias were studied. GM-CSF mRNA was not detected in a total of 11 cases of acute lymphoblastic leukemia (ALL), or 4 cases of CML. 7 of these cases of ALL and 2 cases of CML are shown in Fig. 2.

Since GM-CSF transcripts were detected in AML cells, we sought to determine if the leukemia cells were able to secrete biologically active GM-CSF. We have previously described two cases of AML in which the leukemic cells secreted a CSF-like factor that was biologically and immunologically related to GM-CSF (16). Leukemic cells from each of the 22 cases were cultured at $37^{\circ} \mathrm{C}$ for $48 \mathrm{~h}$, and medium conditioned by these cells was screened for CSF activity using a sensitive quantitative technique that measures CSF-induced DNA synthesis in purified myeloblasts (18). CSF activity is expressed as a stimulation index, the ratio of $\left[{ }^{3} \mathrm{H}\right]$ thymidine incorporation in CSF-treated cells to medium-alone-treated cells. Resting $\mathbf{T}$ cells, marrow mononuclear cells, and purified (unstimulated) monocytes do not secrete detectable CSF. By using a stimulation index of $>1.5$ as indicating the presence of CSF activity, supernatants from $8 / 22$ AML cases were positive (Fig. 3). Six of these cases expressed detectable GM-CSF mRNA (cases 1, 2, 6, 7, 11, 13) and two (cases 8, 19) did not.

Media from six cases in which the stimulation index was $>1.5$ were tested for growth-promoting activity for normal marrow CFU-GM (Table II). In each case, CSF was readily detected for granulocyte-CFU, and in 5 of 6 cases for monocyte-CFU. Media from two cases $(17,21)$ which had no CSF by the screening assay also had no CSF for normal CFU-GM (Table II). The effects of a specific anti-GM-CSF antiserum were determined in five cases in which both GM-CSF mRNA was present and CSF was detected in medium (Table II). Partial or complete inhibition of CFU-GM (particularly monocyte-CFU) was observed in each case, confirming the presence of GM-CSF (or a CSF very similar to GM-CSF) in these five cases.

The expression of GM-CSF mRNA, response to GM-CSF, and CSF secretion are summarized in Table III. 9 of 11 cases expressing GM-CSF mRNA responded to GM-CSF in agar culture, as did 6 of 11 cases lacking GM-CSF mRNA (see Table III). 6 of 11 cases expressing GM-CSF mRNA secreted biologically active CSF, and 2 of 11 cases not expressing GM-CSF mRNA also secreted a CSF. There was no correlation between spontaneous L-CFC growth and GM-CSF mRNA expression.

\section{Discussion}

Each of the human CSFs stimulates proliferation of specific populations of progenitor cells, and also stimulates functional 


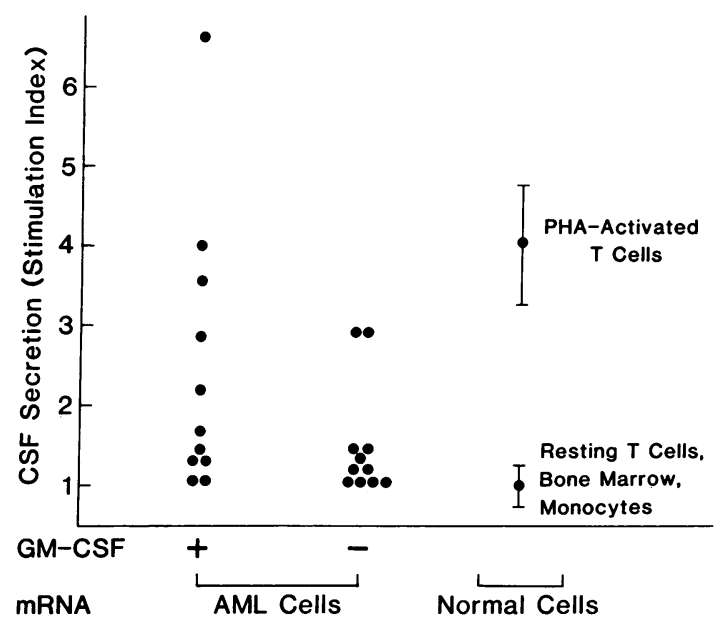

Figure 3. CSF secretion by AML and normal hematopoietic cells. Medium conditioned by $1 \times 10^{6} \mathrm{cells} / \mathrm{ml} \times 48 \mathrm{~h}$ was assayed for CSF activity. Purified myeloblasts were cultured with $10 \%$ conditioned medium as described in Methods. $\left[{ }^{3} \mathrm{H}\right] \mathrm{TdR}$ incorporation in these cells is a direct measure of CSF concentration. The stimulation index (cpm from conditioned medium/cpm medium control) is shown on the $y$ axis. Medium control was $481 \pm 24 \mathrm{cpm}$. AML cases were divided into those expressing the GM-CSF gene (+) and those without GM-CSF transcripts $(-)$. Normal cells (mean \pm SEM, $n=4$ ) are shown for comparison.

activities of granulocytes, monocytes, or both (24). GM-CSF and G-CSF appear to have a broad range of activity, and MCSF a very restricted range. In a previous study, we have demonstrated that GM-CSF is active in vitro in promoting proliferation of leukemic clonogenic cells in AML (13). Preliminary results with recombinant G-CSF and M-CSF indicate that GCSF is active as a single factor in promoting growth of L-CFC and in some cases is synergistic with GM-CSF, while M-CSF has little growth factor activity for AML cells (14). The normal cells that secrete each type of CSF are not completely defined. GM-CSF is produced by activated but not resting $T$ lymphocytes $(9,15)$. Importantly, Nimer and colleagues, using a sensitive "dot blot" analysis, showed that GM-CSF message was not detectable in normal hematopoietic cells other than $\mathrm{T}$ lymphocytes (15), and those results have been confirmed in this study using Northern blot analysis.

In an effort to investigate mechanisms that might contribute to abnormal leukemic cell proliferation in AML, we have investigated the expression of the GM-CSF gene in normal hematopoietic cells and leukemic cells from patients with AML, ALL, and CML. The results presented here show that in 11 of 22 cases of AML the gene was expressed constitutively. The detection of GM-CSF message was not due to the presence of contaminating $\mathrm{T}$ cells, as the number of $\mathrm{T}$ lymphocytes present in each specimen had been reduced to less than detectable levels prior to extraction of cellular RNA, and when the Northern blots were rehybridized with a probe specific for a "marker" $T$ cell message (the alpha chain of the $T$ cell antigen receptor), no detectable T cell RNA was found in any specimen.

Several possibilities can be considered to explain the presence of GM-CSF message in AML cells. First, we considered the possibility that GM-CSF is produced normally by marrow hematopoietic cells. However, GM-CSF message was not detected in $\mathrm{T}$ cell-depleted marrow cells even when stimulated by agents such as PMA that are known to promote expression of the GM-CSF gene in T lymphocytes. It is possible that very immature granulocyte/monocyte progenitor cells express the GMCSF gene, and since these cells are uncommon cells in the marrow, the message could be below the level of detectability in our system. Autocrine secretion of GM-CSF by normal hematopoietic progenitor cells seems unlikely, however, since these cells have never been observed to proliferate autonomously and medium conditioned by monocyte and $\mathrm{T}$ cell-depleted marrow cells does not contain CSF activity. Second, it is possible that normal granulocyte/monocyte precursor cells do not express the GM-CSF gene under normal conditions, but may be activated to express the gene by specific humoral or environmental factors. We have investigated two such factors (PMA and gamma interferon), and neither was found to induce the GM-CSF gene in normal marrow cells. In contrast, PMA induces GM-CSF gene expression in $\mathrm{T}$ lymphocytes, and gamma interferon induces expression of the G-CSF gene and the M-CSF gene in normal monocytes (data not shown). Third, it is possible that the GMCSF is aberrantly expressed in some cases of AML, and that this expression may contribute to the abnormal growth properties of AML.

It is unlikely that autocrine secretion of a CSF could be the cause of AML, since in the absence of at least a partial block in differentiation, it should not be possible to produce a disorder such as AML. It is possible, however, that several cellular events

Table II. Effects of Anti-GM-CSF on CSF Secreted by AML Cells

\begin{tabular}{|c|c|c|c|c|c|}
\hline \multirow[b]{3}{*}{ Case no. } & \multirow{3}{*}{$\begin{array}{l}\text { Stimulation } \\
\text { index }\end{array}$} & \multicolumn{4}{|c|}{$\begin{array}{l}\text { CFU-GM/5 } \times 10^{4} \\
\text { Normal marrow cells }{ }^{\ddagger}\end{array}$} \\
\hline & & \multicolumn{2}{|c|}{ Control } & \multicolumn{2}{|c|}{ Anti-GM-CSF } \\
\hline & & Gran & Mono & Gran & Mono \\
\hline 1 & 3.6 & 141 & 26 & 32 & 0 \\
\hline 2 & 2.2 & 101 & 27 & 0 & 2 \\
\hline 6 & 6.6 & 153 & 18 & 61 & 1 \\
\hline 7 & 1.7 & 164 & 30 & 29 & 0 \\
\hline 8 & 2.8 & 110 & 0 & NT & NT \\
\hline 11 & 4.0 & 152 & 31 & 14 & 0 \\
\hline 17 & 1.0 & 0 & 0 & 0 & 0 \\
\hline 21 & 1.0 & 0 & 0 & 0 & 0 \\
\hline Control medium & - & 0 & 0 & 0 & 0 \\
\hline Control + GM-CSF & - & 103 & 27 & 0 & 0 \\
\hline
\end{tabular}

NT, not tested.

* Stimulation index values are from Fig. 3.

${ }^{\ddagger}$ Medium conditioned by AML cells $\left(1 \times 10^{6}\right.$ cells $/ \mathrm{ml}$ for $\left.48 \mathrm{~h}\right)$ was used to stimulate growth of normal human marrow (light density, nonadherent) CFU-GM by incorporating AML medium in the bottom layer of a double layer agar system ( $10 \%$ final concentration). Control medium was medium without added cells. Control + GMCSF was medium to which recombinant human GM-CSF was added (1:1,000 dilution of CHO-conditioned medium). Control rabbit serum or anti-GM-CSF serum was added at a final dilution of 1:200. Neither control nor anti-GM-CSF sera were inhibitory or stimulatory to normal marrow CFU-GM at the concentration tested. Granulocyte (Gran) and monocyte (Mono) CFU-GM were counted at $7 \mathrm{~d}$ of culture following in situ staining for alpha-naphthyl acetate esterase and chloroacetate esterase activities. All aggregates of $>8$ cells were counted. Mixed Gran/Mono CFU-GM were scored as granulocyte in these experiments. The results are expressed as mean of duplicate cultures. $\mathrm{SD}< \pm 20 \%$ in each case. 
Table III. Correlation of GM-CSF mRNA, Response to GM-CSF, and GM-CSF Secretion*

\begin{tabular}{|c|c|c|c|c|c|c|}
\hline \multirow[b]{2}{*}{ Case no. } & \multirow[b]{2}{*}{ GM-CSF mRNA } & \multirow{2}{*}{$\begin{array}{l}\text { Spontaneous L-CFC } \\
\text { growth }\end{array}$} & \multicolumn{2}{|c|}{ Response to GM-CSF" } & \multirow[b]{2}{*}{ CSF secretion' } & \multirow[b]{2}{*}{ Anti-GM-CSF** } \\
\hline & & & Colony no. & Colony size & & \\
\hline 1 & + & - & + & + & + & + \\
\hline 2 & + & + & + & + & + & + \\
\hline 3 & - & + & + & + & - & NT \\
\hline 4 & - & - & + & + & - & NT \\
\hline 5 & + & - & + & + & - & NT \\
\hline 6 & + & + & - & + & + & + \\
\hline 7 & + & - & - & - & + & + \\
\hline 8 & - & + & - & - & + & NT \\
\hline 9 & + & - & + & + & - & NT \\
\hline 10 & - & - & + & + & - & NT \\
\hline 11 & + & - & - & + & + & + \\
\hline 12 & - & - & - & - & - & NT \\
\hline 13 & + & - & + & + & + & NT \\
\hline 14 & - & - & + & + & - & NT \\
\hline 15 & - & + & - & - & - & NT \\
\hline 16 & - & - & - & - & - & NT \\
\hline 17 & - & + & - & - & - & - \\
\hline 18 & - & + & + & + & - & NT \\
\hline 19 & - & + & + & + & + & NT \\
\hline 20 & + & - & + & + & - & NT \\
\hline 21 & + & - & - & - & - & - \\
\hline 22 & + & + & - & + & - & NT \\
\hline
\end{tabular}

* Table summaries (number of cases in each category):

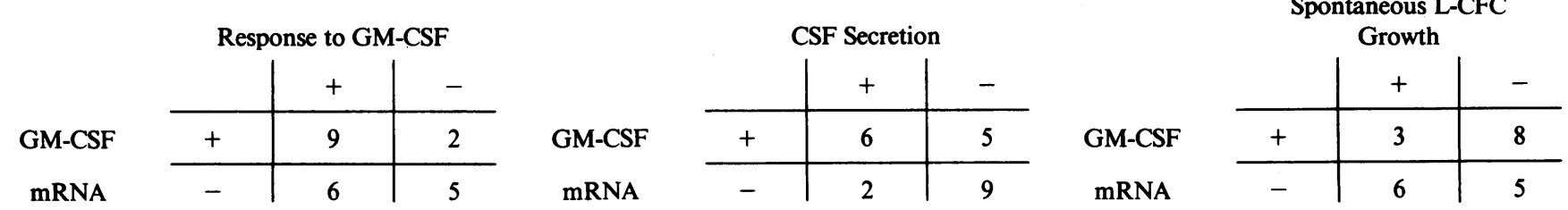

mRNA

mRNA

mRNA

${ }^{\ddagger}$ From Fig. 1. ${ }^{8}$ From Table I, spontaneous growth considered as $>50 \mathrm{~L}-\mathrm{CFC} / 5 \times 10^{4}$ cells. "From Table I, an increase in L-CFC number by $>2$-fold in response to added GM-CSF was considered as + . An increase in estimated colony diameter of $>2$-fold was similarly considered as + for colony size. ' From Fig. 3, stimulation index of $>1.5$ was considered + . "** From Table II.

must take place to generate acute leukemia. Given the fact that AML cells use GM-CSF to proliferate in vitro (13), it is possible that production of this factor by leukemic cells contributes substantially to the excessive cellular proliferation characteristic of AML. To investigate this point further, we have measured CSF activity in medium conditioned by a variety of normal and leukemic cells. Using a sensitive screening bioassay, we detected CSF activity in 6 of the 11 cases in which GM-CSF message was present. Five of these cases were further shown to secrete CSF for normal marrow CFU-GM. In each case partial or complete neutralization of the GM-CSF activity was observed following the addition of specific anti-GM-CSF antibody. These results suggest that these cases are secreting a biologically active CSF that is both molecularly and immunologically similar to GM-CSF. It is possible that other CSFs are also being secreted by some cases. Since the bioassay used here for CSF activity would not distinguish between GM-CSF, G-CSF, or "novel" CSFs, expression of other CSF genes should be determined in AML.

In several cases in which GM-CSF mRNA was found, no biologically active GM-CSF was detected in the medium. This could be partly due to the adsorption of CSF by the leukemic cells themselves, but other possibilities must be considered. For example, GM-CSF could be used by some leukemic cells to augment proliferation by a novel method such as intracellular use or membrane expression. The results of Nara and McCulloch (24) are of interest in this regard. They showed that purified cell membranes from the cells of some AML patients, but not normal marrow or ALL cells, could promote proliferation of other AML cells in short-term liquid suspension culture. Further studies will be required to determine if this factor is GM-CSF. If so, this suggests that AML cells could cross-stimulate other leukemic cells in conditions of high cell concentration either by cell membrane expression or actual secretion of GM-CSF. It is also possible that the mRNA present in these cells is abnormal and either not translatable or being translated into an inactive protein.

Further work will be required to determine the cause of constitutive GM-CSF gene expression in AML. Although deletions of all or part of the fifth chromosome (which contains the GM-CSF gene) (25) are observed in a small fraction of cases of AML, this fraction is not large enough to account for the high incidence of expression of GM-CSF in the cases studied here. 
Small deletions, additions, or point mutations, however, are known to cause activation of genes (26), and would not result in macroscopic chromosomal abnormalities. An extensive Southern blot analysis of AML cell DNA will be required to determine the incidence of structural abnormalities of the GMCSF gene and various regulatory sequences within or adjacent to the gene. Of particular importance would be the identification of promoter or enhancer sequences and studies to determine their activity in AML.

It will be of interest to determine if all leukemic cells in a given patient or only a fraction secrete GM-CSF. Preliminary cell sorting experiments with monoclonal antibodies MY7, MY9, and MY4 have indicated that leukemic cells of both early and late stages of differentiation can secrete GM-CSF, and that this is not restricted to leukemic monocytes.

While expression of a CSF gene has not previously been reported in fresh human myeloid leukemias, one myeloid cell line, HL-60, has been reported to secrete an autostimulatory factor (27). The production of CSFs by certain murine and avian leukemic cells has been documented. For example, the murine myeloid leukemia cell line WEHI-3B constitutively secretes multi-CSF (interleukin-3) apparently due to insertion of a retroviral sequence adjacent to the multi-CSF gene (28). Chicken myeloid cells transformed by $v-m y b$ or $v$-myc-containing leukemia viruses require chicken CSF for in vitro proliferation (29, 30). Superinfection with retroviruses containing src or mil oncogenes induces autonomous growth due to autocrine secretion of chicken CSF. Further evidence that CSF genes may contribute to the pathogenesis of leukemia has been provided by Lang and colleagues (31), who showed that transfection of the murine GMCSF gene into a CSF-dependent nonleukemic myeloid cell line produced leukemic cell lines that constitutively secreted GM-CSF.

The results presented here show that the GM-CSF gene is expressed in the leukemic cells of a subset of patients with AML. In some of the cases, biologically active CSF could be detected in medium conditioned by the AML cells, while in other cases no CSF secretion could be identified. In these cases in particular, it will be of interest to determine if membrane or cytoplasmic CSF activity can be detected. Our finding that expression of this gene is not detectable in acute lymphoblastic leukemia, chronic myeloid leukemia, or in normal bone marrow myeloid cells suggests that expression of the GM-CSF gene may be a useful molecular marker for AML. Finally, while expression of a CSF gene would not by itself cause leukemia, it could serve in some capacity to promote the proliferation of leukemic cells in vivo.

\section{Acknowledgment}

This work was supported by Public Health Service grants CA-19389 and CA-36167.

\section{References}

1. Buick, R. N., J. E. Till, and E. A. McCulloch. 1977. Colony assay for proliferative blast cells circulating in myeloblastic leukemia. Lancet. 1:862-863.

2. Buick, R. N., M. D. Minden, and E. A. McCulloch. 1979. Selfrenewal in culture of proliferative blast progenitor cells in acute myeloblastic leukemia. Blood. 54:95-104.

3. Wouters, R., and B. Löwenberg. 1984. On the maturation order of AML cells; a distinction on the basis of self-renewal properties and immunologic phenotypes. Blood. 63:684-689.

4. Griffin, J. D., P. Larcom, and S. F. Schlossman. 1983. Use of surface markers to identify a subset of acute myelomonocytic leukemia cells with progenitor cell properties. Blood. 62:1300-1303.

5. Minden, M. D., J. E. Till, and E. A. McCulloch. 1978. Proliferative state of blast cell progenitors in acute myeloblastic leukemia (AML). Blood. 52:592-600.

6. Griffin, J. D., and B. Löwenberg. 1986. Clonogenic cells in acute myeloblastic leukemia. Blood. In press.

7. Griffin, J. D., D. Young, F. Herrmann, D. Wiper, K. Wagner, and K. D. Sabbath. 1986. Effects of recombinant GM-CSF on proliferation of clonogenic cells in acute myeloblastic leukemia. Blood. 67:1448-1453.

8. Ozawa, K., Y. Miura, T. Suda, K. Motoyoshi, and F. Takaku. 1983. In vitro differentiation of leukemic progenitor cells in various types of acute nonlymphocytic leukemia. Cancer Res. 43:2334-2338.

9. Wong, G. G., J. S. Witek, P. A. Temple, K. M. Wilkens, A. C. Leary, D. P. Luxemberg, S. S. Jones, E. L. Brown, R. M. Kay, E. C. Orr, C. Shoemaker, D. W. Golde, R. J. Kaufman, R. M. Hewick, E. A. Wang, and S. C. Clark. 1985. Human GM-CSF. Molecular cloning of the complementary DNA and purification of the natural and recombinant proteins. Science (Wash. DC). 228:810-815.

10. Nagata, S., M. Tsuchiya, S. Asano, Y. Kaziro, T. Yamazaki, O. Yamamoto, Y. Hirata, N. Kubota, M. Oheda, H. Nomura, and M. Ono. 1986. Molecular cloning and expression of cDNA for human granulocyte colony-stimulating factor. Nature (Lond.). 319:415-418.

11. Souza, L., T. C. Boone, J. Gabrilove, P. H. Lai, K. M. Zsebo, D. C. Murdock, V. R. Chazin, J. Bruszewski, H. Lu, K. K. Chen, J. Barendt, E. Platzer, M. A. S. Moore, R. Mertelsmann, and K. Welte. 1986. Recombinant human granulocyte colony-stimulating factor: Effects on normal and leukemic myeloid cells. Science (Wash. DC). 232:61-65.

12. Kawasaki, E. S., M. B. Ladner, A. M. Wang, J. Van Arsdell, M. K. Warren, M. Y. Coyne, D. L. Schwickart, M. Lee, K. J. Wilson, A. Boosman, E. R. Stanley, P. Ralph, and D. F. Mark. 1985. Molecular cloning of a complementary DNA encoding human macrophage-specific colony-stimulating factor (CSF-1). Science (Wash. DC). 230:291-296.

13. Sabbath, K. D., E. D. Ball, P. Larcom, R. B. Davis, and J. D. Griffin. 1985. Heterogeneity of clonogenic cells in acute myeloblastic leukemia. J. Clin. Invest. 75:746-753.

14. Vallerga, E., D. C. Young, K. Wagner, D. Wiper, D. Ostapovitz, and J. D. Griffin. Synergy between G-CSF and GM-CSF in promoting growth of clonogenic cells in acute myeloblastic leukemia. (Submitted).

15. Nimer, S. D., J. Chan, D. J. Slamon, D. W. Golde, and J. D. Gasson. 1985. Expression of human granulocyte-macrophage colony stimulating factor (GM-CSF). Blood. 66:158a. (Abstr.)

16. Young, D. C., and J. D. Griffin. 1986. Autocrine secretion of GM-CSF in acute myeloblastic leukemia. Blood. In press.

17. Griffin, J. D., J. Ritz, L. M. Nadler, and S. F. Schlossman. 1981. Expression of myeloid differentiation antigens on normal and malignant myeloid cells. J. Clin. Invest. 68:932-941.

18. Griffin, J. D., R. Sullivan, R. P. Beveridge, P. Larcom, and S. F. Schlossman. 1984. Induction of proliferation of purified human myeloid progenitor cells. A rapid assay for granulocyte colony-stimulating factors. Blood. 63:904-911.

19. DiPersio, J. F., J. K. Brennan, M. A. Lichtman, and B. L. Speiser. 1978. Human cell lines that elaborate colony-stimulating activity for the marrow cells of man and other species. Blood. 51:507-519.

20. Feinberg, A. P., and B. Vogelstein. 1983. A technique for radiolabelling DNA restriction endonuclease fragments to high specific activity. Anal. Biochem. 132:6-13.

21. Royer, H. D., D. Ramarli, O. Acuto, T. J. Campen, and E. L. Reinherz. 1985. Genes encoding the T-cell receptor alpha and beta subunits are transcribed in an ordered manner during intrathymic ontogeny. Proc. Natl. Acad. Sci. USA. 82:5510-5514.

22. Bennet, J. M., D. Catovsky, M.-T. Daniel, G. Flandrin, D. A. G. Galton, H. Gralnick, and C. Sultan. 1985. Proposed revised criteria for the classification of acute myeloid leukemia. A report of the 
French-American-British Cooperative Group. Ann. Intern. Med. 103: 620-625.

23. Nadler, L. M., J. Ritz, J. D. Griffin, R. F. Todd, E. L. Reinherz, and S. F. Schlossman. 1981. Diagnosis and treatment of human leukemias and lymphomas utilizing monoclonal antibodies. Prog. Hematol. 12: 187-225.

24. Nara, N., and E. A. McCulloch. 1985. Membranes replace irradiated blast cells as growth requirement for leukemic blast progenitors in suspension culture. J. Exp. Med. 162:1435-1443.

25. Huebner, K., I. Masaharu, C. M. Croce, D. W. Golde, S. E. Kaufman, and J. C. Gasson. 1985. The human gene encoding GM-CSF is at 5q21-q32, the chromosome region deleted in the 5q- anomaly. Science (Wash. DC). 230:1282-1285.

26. Capon, D. J., E. Y. Chen, A. D. Levinson, P. H. Seeburg, and D. V. Goeddel. 1983. Complete nucleotide sequences of the T24 human bladder carcinoma oncogene and its normal homologue. Nature (Lond.). 302:33-37.

27. Brennan, J. K., C. N. Abboud, J. F. DiPersio, G. H. Barlow, and
M. A. Lichtman. 1981. Autostimulation of growth by human myelogenous leukemia cells (HL-60). Blood. 58:803-812.

28. Ymer, S., Q. J. Tucker, C. J. Sanderson, A. J. Hapel, H. D. Campbell, and I. G. Young. 1985. Constituitive synthesis of interleukin3 by leukemia cell line WEHI-3B is due to retroviral insertion near the gene. Nature (Lond.). 317:255-258.

29. Adkins, B., A. Leutz, and T. Graf. 1984. Autocrine growth induced by $s r c$-related oncogenes in transformed chicken myeloid cells. Cell. 39: 439-445.

30. Graf, T., F. V. Weizsaeker, S. Grieser, J. Coll, D. Stehelin, T. Patschinsky, K. Bister, C. Bechade, G. Calothy, and A. Leutz. 1986. vmil induces autocrine growth and enhanced tumorigenicity in v-myctransformed avian macrophages. Cell. 45:357-374.

31. Lang, R. A., D. Metcalf, N. M. Gough, A. R. Dunn, and T. J. Gonda. 1985. Expression of a hemopoietic growth factor cDNA in a factor-dependent cell line results in autonomous growth and tumorigenicity. Cell. 43:531-542. 